\title{
Prolonged receptivity to the male and the fate of spermatozoa in the female black mastiff bat, Molossus ater
}

\author{
J. J. Rasweiler IV \\ Department of Obstetrics and Gynecology, Cornell University Medical College, \\ 515 East 71st Street, New York, NY 10021, U.S.A.
}

\begin{abstract}
Summary. Observations were made on the reproductive biology of black mastiff bats maintained in a laboratory colony. Many of the females were inseminated within $24 \mathrm{~h}$ after the introduction of the males, and most exhibited a period of 10-50 days during which spermatozoa were present in their vaginal smears almost every day. The frequency of sperm-positive smears began to fall off around the time of implantation, but some smears taken much later in pregnancy were positive. The extent to which spermatozoa in the smears came from reservoirs in the female tract could not be thoroughly investigated, but evidence was obtained that the females have more than a limited period of oestrus. Female courtship behaviour and new copulations were sometimes observed many days after the start of the breeding activity. Also, histological studies of the reproductive tracts of females which had recently mated revealed that many were not in a periovulatory condition. Intact spermatozoa were usually found in the uterine horns and distal oviducts of preovulatory bats and those carrying tubal ova. Spermatozoa were absent from the oviducts of animals bearing early uterine embryos, and were much less abundant in the uterine horns after the start of implantation. Many of the excess spermatozoa appeared to have been expelled into the upper cervix where phagocytic leucocytes were commonly observed in the lumen. Some sperm components were also taken up by epithelial cells in the oviducts and uterine horns.
\end{abstract}

\section{Introduction}

The black mastiff bat (Molossus ater) is a relatively large insectivorous species which occurs widely in the New World tropics from southern Mexico to southern Brazil, Paraguay and northern Argentina (Cabrera, 1958; Hall \& Kelson, 1959; Villa, 1966; Koopman, 1978; K. F. Koopman, personal communication; Dolan, 1982; Myers \& Wetzel, 1983). Since this bat is colonial and often roosts in buildings, as well as hollow trees, it is frequently regarded as a nuisance and is of some public health interest.

In addition to scattered, brief comments on the reproductive status of wild-caught specimens, relatively little is known about reproduction in black mastiff bats. Observations were made by Sansom (1932) on early uterine embryos in two species of Molossus including Molossus rufus ( = M. ater). Wimsatt $(1975,1979)$ noted that $M$. ater, like nearly all other members of the family Molossidae examined to date (Krutzsch \& Crichton, 1985; van der Merwe et al., 1986) exhibits a dextral dominance in functioning of the reproductive tract. Ovulation has been found to occur only from the right ovary, with implantation then taking place in the right uterine horn. The morphogenesis of the chorioallantoic placenta in the black mastiff bat is also of interest since this organ appears to develop only at the cranial end of the right uterine horn (J. J. Rasweiler, unpublished observations). 
To investigate the factors which determine the positioning of the chorioallantoic placenta, methods have been devised for maintaining and breeding this species in the laboratory. The present paper deals with the breeding biology of the black mastiff bat. Among other observations spermatozoa were found in the daily vaginal smears from many of the females for unusually long periods of time, thus raising the possibility that oestrus is prolonged in this bat and/or that the females are capable of storing spermatozoa. Considerable attention will therefore be focussed upon both the timing of female receptivity to the male and the fate of the spermatozoa in the female tract.

\section{Materials and Methods}

Animal procurement. All of the bats utilized in this study were captured with mist nets as they left their roosts in buildings in central Trinidad, West Indies, in order to forage at dusk or dawn.

Animal maintenance. Following their transport to Cornell University Medical College, the bats were maintained in a warm room $\left(29-31^{\circ} \mathrm{C}\right)$ with a controlled light cycle $(12 \mathrm{~h}$ light:12 h dark). They were housed in groups in Jewell animal cages $(45.7 \mathrm{~cm}$ deep $\times 48.3 \mathrm{~cm}$ wide $\times 35.6 \mathrm{~cm}$ high). A portion of each cage was almost completely enclosed to provide a darkened, diurnal roosting area $(45.7 \mathrm{~cm}$ deep $\times 15.2 \mathrm{~cm}$ wide $\times 27.9 \mathrm{~cm}$ high). The bats could enter the enclosed compartments via a floor level access hole $(7.6 \mathrm{~cm}$ wide $\times 5.1 \mathrm{~cm}$ high). The front of this compartment consisted of a sliding aluminum door which ran on a separate track inside the main cage door.

The bats were maintained on water and mealworms (the larvae of Tenebrio molitor) offered ad libitum. The water was provided via chick fountains, consisting of a reservoir bottle and water trough. The mealworms were served in shallow, polyethylene trays $(3.8 \times 19.7 \times 24.8 \mathrm{~cm})$ with sloping sides which prevented their escape (Gage Industries Inc., Lake Oswego, OR, U.S.A.). Initially the mealworms were fattened for 2-3 weeks on a culture medium composed of 47.5\% wheat bran, 47.5\% ground High Protein Monkey Chow 5045 (Ralston Purina, St Louis, Missouri, U.S.A.) and powdered calcium carbonate $(5.0 \%)$. Immediately before being offered to the bats, each $100 \mathrm{~g}$ mealworms was sprayed with $0.5 \mathrm{ml}$ Avitron Liquid Vitamin Supplement (Lambert Kay, Division of Carter-Wallace Inc., Cranbury, NJ, U.S.A.) diluted with an equal volume of water. Maintenance of the larvae on the supplemented medium elevated their calcium levels, but the calcium:phosphorus ratio of the mealworms was still outside the range generally considered adequate for good mammalian nutrition (J. J. Rasweiler, unpublished observations). Therefore, for the remainder of the study the mealworms were stored as received from the supplier (i.e. packed in crumpled newspapers) in a cold room $\left(8^{\circ} \mathrm{C}\right)$. Then, immediately before being offered to the bats, they were sprayed with Avitron and dusted directly with calcium carbonate ( $0.8 \mathrm{~g}$ per $100 \mathrm{~g}$ mealworms).

Animal breeding. During the initial phases of the study, when cage space was at a premium due to some unanticipated problems, three breeding groups were established consisting of 1 male and 13-15 females. Subsequently the practice was to house 1 male with 8 females for breeding purposes.

Timing of reproductive stages. Smears were obtained from the females each morning by aspirating a small amount of distilled water in the vagina with a microeyedropper. The latter consisted of a pipette nipple, a piece of glass tubing ( $50 \mathrm{~mm}$ long, $8 \mathrm{~mm}$ o.d.) and a serum sleeve type rubber stopper $(7 \times 11 \mathrm{~mm})$ through which a fire-polished capillary tube ( $75 \mathrm{~mm}$ long, $1.2 \mathrm{~mm}$ i.d.) was mounted. Separate microeyedroppers were used each day for each bat. These were flushed thoroughly with water after use to eliminate the possible carryover of spermatozoa. Initially the smears were examined for spermatozoa by phase-contrast microscopy. Frequently, however, only very small numbers of sperm heads were present. Since these were difficult to find by phase-contrast microscopy when intermingled with a great excess of vaginal epithelial cells, another method for examining the smears had to be adopted. The smears were therefore dried, fixed in absolute methanol and stained for $30 \mathrm{~min}$ in a solution of $4 \mathrm{ml}$ Gurr's Improved R66 Giemsa

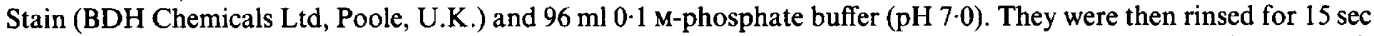
in distilled water and dried. Many of the sperm nuclei were stained reddish-purple by this procedure and were much easier to detect amongst the vaginal epithelial cells with their bluish cytoplasm. To monitor changes in the relative abundance of spermatozoa in the daily smears, the ratio of spermatozoa to vaginal epithelial cells was roughly assessed and recorded using a scoring system $( \pm,+,++)$. Since several thousand smears had to be examined, it was not feasible to carry out more quantitative studies.

Histological procedures. In view of the fact that prolonged sperm storage occurs in some female bats, consideration had to be given to the possibility that this may also play a role in the extended presence of spermatozoa in the vaginal smears of black mastiff bats. Because the ultimate goal of this study was to examine placental development, it was not deemed advisable to remove the males shortly after the onset of breeding activity and then to check the females at various intervals for surviving spermatozoa. Instead, many of the tracts could only be examined histologically for possible sperm storage sites.

All bats were killed between $09: 00$ and 12:00 h for the histological studies. The conceptuses were removed when possible, fixed separately, measured and weighed. The reproductive tracts of the females were fixed in Zenker's fluid for 10-12 h, washed overnight in running tap water and processed through graded ethyl alcohols, cedar wood oil and Histosol (National Diagnostics, Inc., Somerville, NJ, U.S.A.) to paraffin wax. Most of the tracts were then serially 
sectioned at $6 \mu \mathrm{m}$. Near the end of pregnancy only the ovaries and the portion of the uterus containing the chorioallantoic placenta were serially sectioned, and the observations on some of the tracts are therefore incomplete. The histological sections were then stained with haematoxylin and eosin, Masson's trichrome procedure, or the periodic acid-Schiff (PAS) technique and haematoxylin. Some sections from each tract were incubated for $1 \mathrm{~h}$ at $37^{\circ} \mathrm{C}$ in $0 \cdot 1 \%$ $\alpha$-amylase (1,4- $\alpha$-D-glucan-glucanohydrolase; Sigma Chemical Company, St Louis, MO, U.S.A.) dissolved in a $0.02 \mathrm{M}$-phosphate buffer ( $\mathrm{pH}$ 6) to remove any glycogen before being stained by the PAS procedure. Parallel sections were incubated under similar conditions in the buffer alone and then stained. The glycogen-hydrolysing ability of the enzyme solution was confirmed by tests on sections of liver and skeletal muscle.

\section{Results}

\section{Reproductive behaviour}

Black mastiff bats possess a large gland at the base of their throats which is prominent in adult males but non-functional in females (Horst, 1966). This gland appears to play an important role in the bats' courtship behaviour. Females in the captive colony sometimes exhibited intense interest in the gular glands of breeding males. Typically one or several of these females would repeatedly

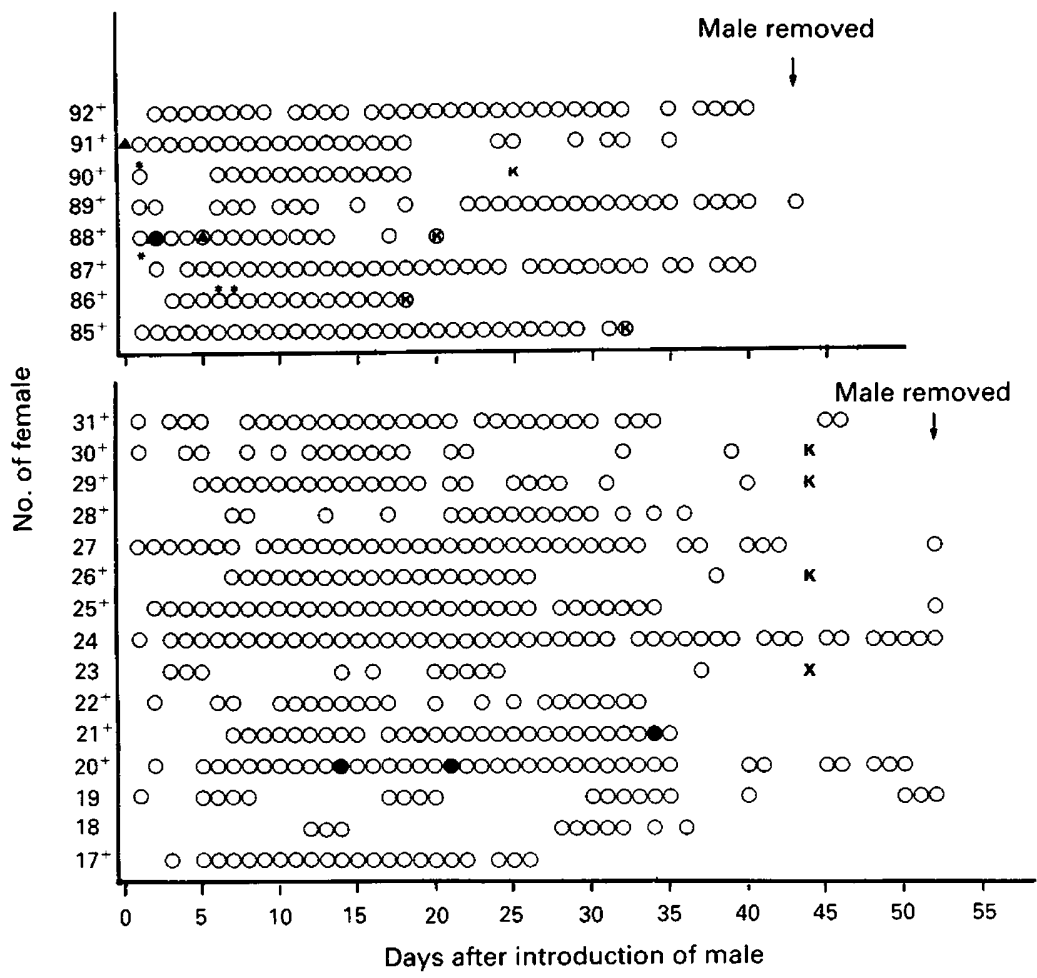

Fig. 1. Days on which sperm-positive smears $(O)$ were obtained from two groups of female black mastiff bats, each housed with a single male. $=$ vaginal plug was present in female; $\mathrm{x}=$ animal died of natural causes; $\mathrm{k}=$ animal killed for experimental reasons; $\boldsymbol{\Delta}=$ coitus was observed; ${ }^{*}=$ female displayed intense sexual interest in male on this day; $+=$ successfully impregnated female.

Behavioural observations were generally limited to those periods ( $1-2 \mathrm{~h}$ per day) when the animals were being cared for or worked with. Some courtship behaviour may not have been recognized in the larger breeding group, one of the first established. After removal of the male from this group, he was immediately placed with 8 non-pregnant females and inseminated 6 of them within $24 \mathrm{~h}$. 
approach a male and attempt to nuzzle his throat region. Throughout these encounters many short, high-pitched chirps could be heard. On a number of occasions apparent interest in the gular gland seemed to lead a female to crawl under the male, into the normal dorsum-to-venter mating position, and coitus eventually took place. This was accompanied by much louder squeals and prominent thrusting on the part of the male.

\section{Breeding performance}

Observations were made on the breeding performance of 99 captive females. Some of these $(\mathrm{N}=43)$ were housed in large breeding groups (13-15 females: 1 male) and the remainder $(\mathrm{N}=56)$ in smaller groups ( 8 females: 1 male). A total of 7 males with prominent testes were selected for use as breeders. Although all of these did breed, 3 inseminated relatively few females during the 7-15 days the sexes were housed together, and these males were replaced by better breeders. In those cages where good stud males were used from the start, 29/70 females were inseminated within the first $24 \mathrm{~h}$ after introduction of the males (Fig. 1). During subsequent weeks sperm-positive smears were obtained from many of the females on any given day, although frequently only very small numbers of spermatozoa or sperm heads could be found in a smear. Furthermore, most of the females exhibited a period of 10-50 days duration during which spermatozoa were present in their smears almost every day. Spermatozoa were usually absent or only sporadically present in the smears before and after this period.

The decrease in sperm-positive smears appeared to be related to the fact that the females had become pregnant, rather than to a change in the libido of the males. In 4 breeding cages many of the females were allowed to continue well into pregnancy or to deliver their young. Nearly all (35/37) of the pregnant animals in these cages exhibited a fall-off in sperm-positive smears, although males were still present. The two bats which did not were killed relatively early in pregnancy and carried only unimplanted uterine embryos. When the males were removed from these cages, they were immediately housed with non-pregnant females and soon exhibited a high level of breeding activity, inseminating $22 / 32$ females within $48 \mathrm{~h}$.

The frequency of sperm-positive smears seemed to fall off around the time of implantation. Almost all (16/17) of the bats bearing healthy vesicular or Graafian follicles, tubal ova or unimplanted uterine embryos had sperm-positive smears until the day of death. The exception was a female carrying a uterine morula, and only her last smear was sperm-negative. Spermatozoa were also observed in the smears of $7 / 13$ females carrying implanting or implanted blastocysts until the day of death; however, in 4 of those 7 females sperm-negative smears were common in the last 6-8 days. The remaining 6 bats with implanting or implanted blastocysts had negative smears for 5-14 days before death.

Spermatozoa were observed sporadically in the vaginal smears of some females well into pregnancy. Sperm-positive smears were obtained within 1 week of death in 7 females found to be carrying well-developed fetuses (4.9-11.4 mm crown-rump length). How much longer this may continue is unclear, since females in advanced pregnancy were not housed with males or subjected to daily smearing.

Several lines of evidence indicate that black mastiff bats exhibit more than a limited period of oestrus. Females sometimes displayed intense interest in the males, were observed copulating, or had new vaginal plugs many days after the start of breeding activity (Fig. 1). In general, however, vaginal plugs were found very infrequently. Furthermore, it was common to observe sudden increases in sperm numbers and changes from broken to intact spermatozoa in the series of vaginal smears from a female well after the onset of breeding. These observations suggest that new inseminations may have taken place. Histological studies of tracts removed from females within 3-10 days after the start of breeding also indicated that this was frequently uncorrelated with a periovulatory reproductive condition (J. J. Rasweiler, unpublished observations). Finally, 2 females had spermpositive smears for 26 and 28 days respectively, immediately before being killed. These bats lacked corpora lutea and had atrophic uteri. 


\section{Distribution of spermatozoa in the female tract}

There were many similarities in the distribution of spermatozoa in most of the mated females which were preovulatory, had a newly ruptured follicle, or carried unimplanted embryos (Table 1). Nearly all (28/29) had spermatozoa in their uterine horns, slightly less (23/29) had spermatozoa in the cranial portion of the cervix into which the horns open, and only 1/29 had spermatozoa in the remainder of the cervical canal. In most of these animals spermatozoa were more abundant in the uterine horns than in the cervix, although in 3 females large numbers of intact spermatozoa were present in both regions. With few exceptions the spermatozoa in the horns lacked the acidophilic and PAS-positive extracellular material which surrounded those in the cervix.

Table 1. Distribution of spermatozoa in the female tracts of mated, captive black mastiff bats

\begin{tabular}{lcccc}
\hline & & \multicolumn{3}{c}{ Number of bats with spermatozoa present } \\
\cline { 3 - 5 } \multicolumn{1}{c}{ Reproductive condition } & $\begin{array}{c}\text { Total no. } \\
\text { of bats }\end{array}$ & $\begin{array}{c}\text { Cranial end } \\
\text { of cervix }\end{array}$ & $\begin{array}{c}\text { Uterine } \\
\text { horns }\end{array}$ & $\begin{array}{c}\text { Junctura of } \\
\text { oviduct }\end{array}$ \\
\hline Non-pregnant, no large follicles or CL & 10 & 9 & 9 & 7 \\
$\begin{array}{l}\text { Non-pregnant with large vesicular or Graafian } \\
\text { follicles }\end{array}$ & 12 & 8 & 12 & 8 \\
Non-pregnant with a newly ruptured follicle & 1 & 1 & 1 & 1 \\
Non-pregnant with recently formed CL & 9 & 5 & 1 & 1 \\
Pregnant with oviducal embryo & 1 & 1 & 1 & -1 \\
Pregnant with unimplanted uterine embryos & 5 & 4 & 5 & - \\
Pregnant with early implanting blastocysts & 2 & 1 & 2 & - \\
Pregnant with implanting or recently implanted & 11 & 5 & 9 & 11 \\
$\quad$ blastocysts & 20 & 5 & &
\end{tabular}

Some spermatozoa were also found in the distal oviduct, most frequently in the intramural segment of the junctura, and less commonly in the isthmus, in many (15/22) of the preovulatory animals and in the 2 bats carrying tubal ova. Spermatozoa were seen in the oviducal ampulla only in 2 of the females with Graafian follicles. There was no suggestion of a special morphological relationship between the spermatozoa and the oviducal epithelium such as has been reported for some of the bats which store spermatozoa (Medway, 1972; Racey et al., 1975; Krishna \& Dominic, 1978; Mōri \& Uchida, 1980; Mōri et al., 1982; Krishna, 1984).

Vaginal plugs were present in 5 of these females when they were killed. Upon histological examination the plugs were found to be limited to the vagina, with spermatozoa being most abundant at the cranial end of the plug. In two of these bats no spermatozoa were present in the cervix, although small numbers (presumably from prior inseminations) were noted in the endometrial glands of the horns.

Spermatozoa were still present in many of the bats carrying implanting or recently implanted blastocysts, but were usually much less abundant in the uterine horns than in previous stages of pregnancy. Furthermore, most of the uterine spermatozoa were broken and a large proportion were located within the endometrial glands. Nearly all of these bats also lacked any oviducal spermatozoa. The 2 animals with the earliest implanting blastocysts were exceptional in that one still had many uterine spermatozoa and the other had a few spermatozoa in the junctura of the left oviduct.

Small numbers of degenerate spermatozoa were observed in the endometrial glands of the non-gravid left horn, and much less frequently in the gravid right horn, in some of the bats carrying 

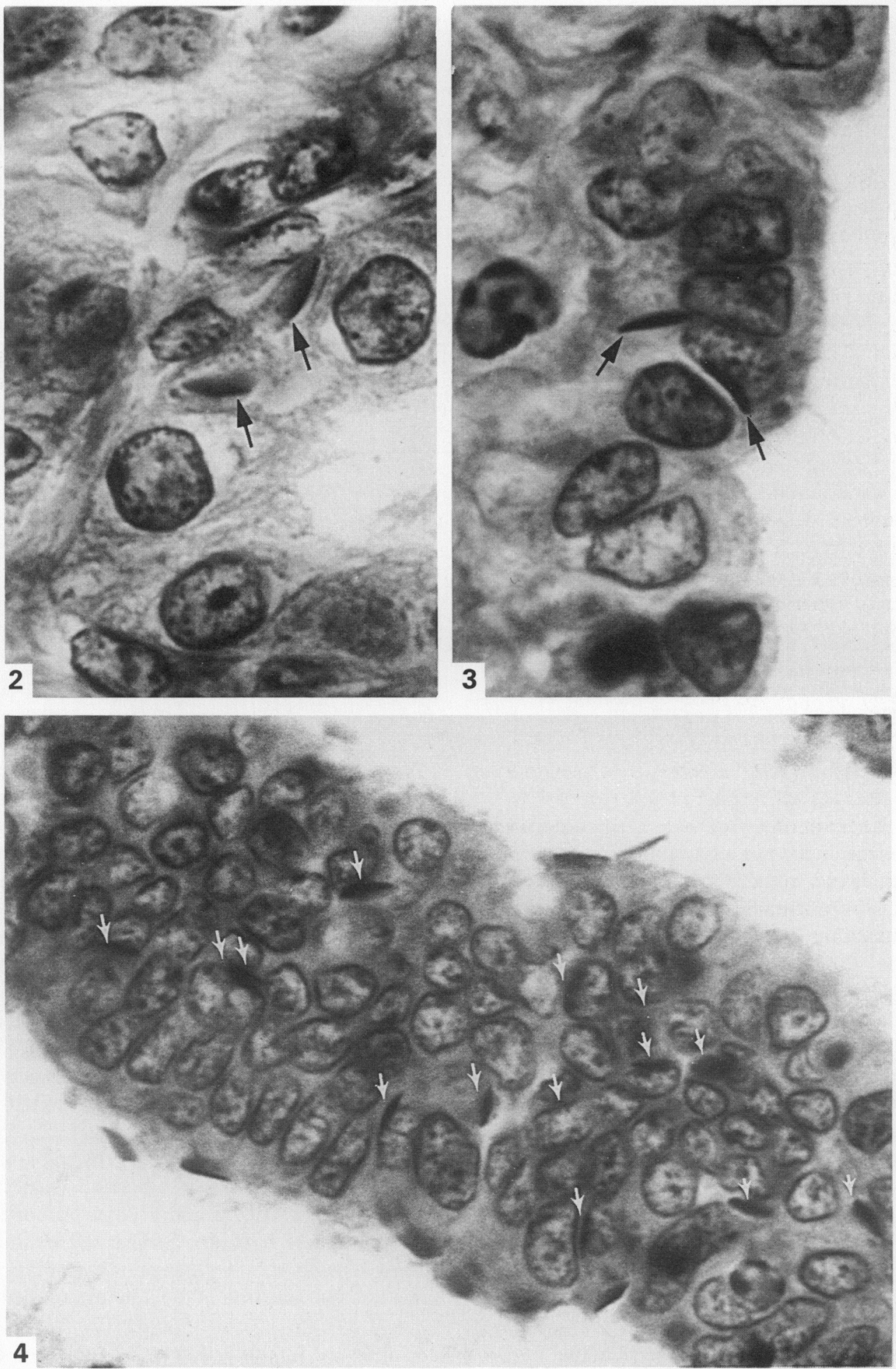
more advanced conceptuses (i.e. somite stage or older). Spermatozoa can apparently persist in these glands for substantial periods during pregnancy. In 3 females (which carried fetuses of 12.1-22.6 mm crown-rump length), spermatozoa were still present in the glands $7-13$ days after removal of the males and $22-53$ days after the last sperm-positive vaginal smear. Small numbers of degenerate spermatozoa were also observed in the cranial end of the cervix in some of these pregnant bats (i.e. in females carrying fetuses up to $9.7 \mathrm{~mm}$ crown-rump length).

Nine non-pregnant, postovulatory females were killed after exhibiting sperm-positive smears for 3-10 days. Although all had recently formed corpora lutea, the general histological appearance of the reproductive tracts strongly suggests that ovulation had occurred well before the start of breeding activity. In 4 of these bats well-developed decidual reactions were evident in the uterine horns. These animals had spermatozoa in the cervices, but none in the uterine horns or oviducts, possibly because closure of the uterine lumen had occurred and interfered with sperm transport. Such closure of the lumina was also noted in bats carrying implanting blastocysts. In 4 other bats much of the endometrium was disorganized and/or necrotic and in the process of being sloughed into the lumen in a menstrual-like fashion. Decidual reactions had begun in all or part of the endometrium in 3 of these animals. In another female, the endometrium was much thinner but the presence of abundant cellular debris in the lumina indicated that a similar sloughing process had occurred. Spermatozoa were absent from the cervix, uterine horns and oviducts in 4 of these bats, but were present in the cervix and left uterine cornu of the fifth animal. In the latter individual a prominent decidual reaction had occurred in the right horn, and had probably interfered with sperm transport on that side, but not in the left horn.

Although spermatozoa were frequently seen at the cranial end of the cervix, they were noted in the remainder of the cervix only in 4/71 tracts. In 3 of these 4 bats decidual reactions had occurred in one or both uterine horns and sperm transport had not occurred into the affected horns.

\section{Fate of spermatozoa in the female tract}

Spermatozoa were moderately abundant in the intramural portion of the oviduct until passage of the embryo into the uterus, but then disappeared from that region. Presumably this is a result of the clearance of most spermatozoa back into the uterus, since no evidence was obtained for their movement at that time in an ovarian direction.

Components of a few spermatozoa were taken up instead by the oviducal epithelium (Fig. 2). Sperm heads were seen within the epithelium in the following bats: $1 / 12$ non-pregnant with large vesicular or Graafian follicles; 2/2 carrying tubal ova; 1/5 carrying unimplanted uterine embryos; and $1 / 2$ carrying early implanting blastocysts. Since the heads were often well within the epithelium

Fig. 2. Section of oviducal isthmus from a bat which had a large Graafian follicle at the germinal vesicle stage in its right ovary. Two sperm heads (arrows) are evident within the epithelium. Masson's trichrome, $\times 2300$.

Fig. 3. Section through the luminal epithelium in the non-gravid, left uterine horn of a bat carrying an early implanting blastocyst. Two sperm heads (arrows) can be seen in the epithelium. PAS-haematoxylin, $\times 2300$.

Fig. 4. Tangential section through a small ridge of luminal epithelium projecting into the nongravid, left uterine horn of a bat carrying an early implanting blastocyst. The arrows indicate the locations of sperm heads (all of which could not be brought into focus simultaneously in the photomicrograph) in the epithelium. With two possible exceptions all of these sperm heads had to be within the epithelium since they were not associated with any PAS-positive material (glycocalyx and/or secretions) clearly evident on the exposed surfaces of the epithelial cells. PAS-haematoxylin, $\times 1687$. 

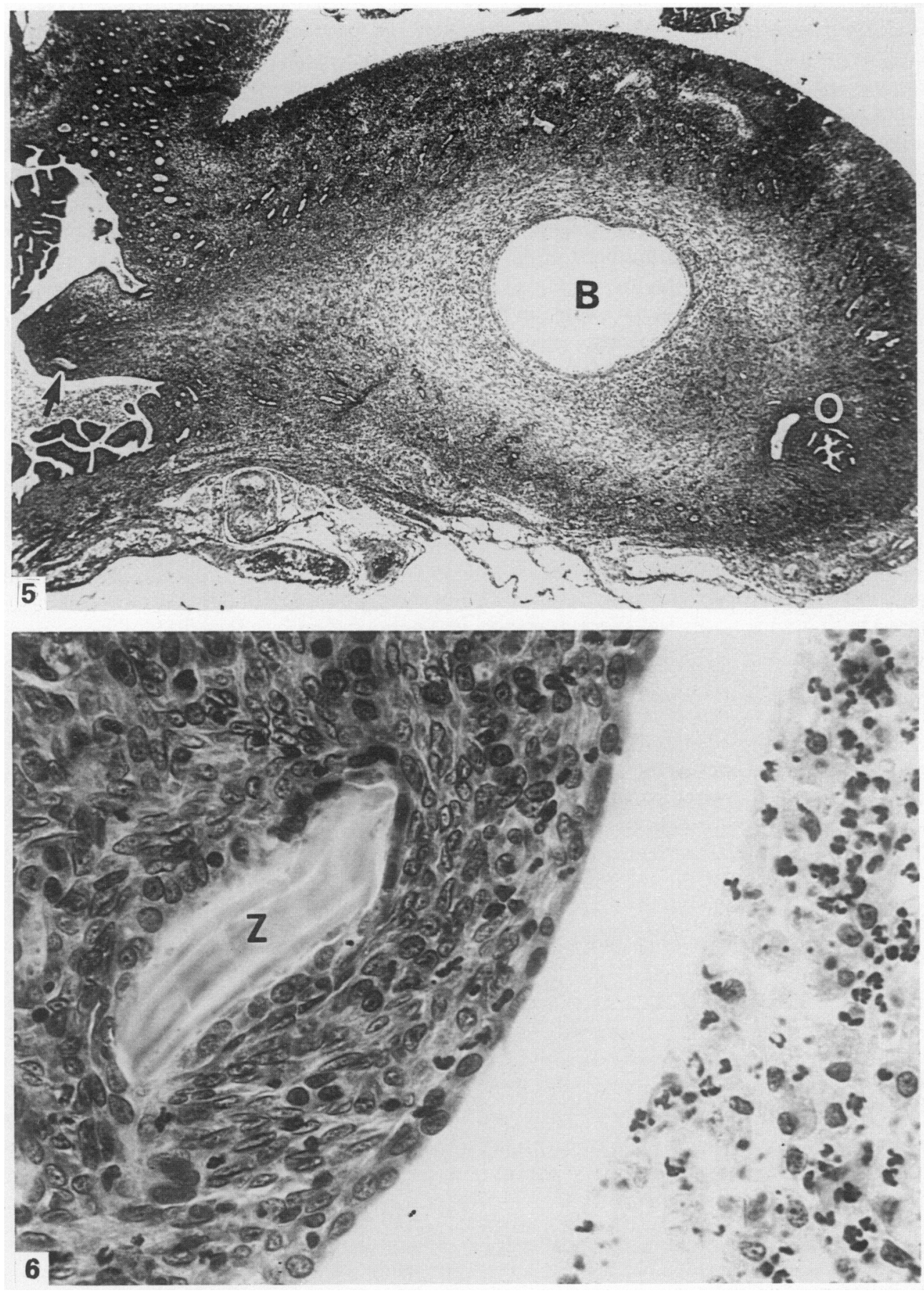

Fig. 5. Frontal sections through the right horn of a uterus which contained a blastocyst (B) at the primitive streak stage. The zona pellucida (arrow) which had surrounded this embryo was found at the extreme cervical end of the horn. $\mathrm{O}=$ intramural portion of the oviduct. Masson's trichrome, $\times 35$. 
and located in the same focal plane as the epithelial cells, their presence there could not be attributed to displacement during histological processing. It was also common in the females carrying tubal and early uterine embryos to see pycnotic nuclei and intensely stained fragments of chromatin in the oviducal epithelium, often within vacuoles. The elongated shapes of some of these nuclei or chromatin masses suggests that they had come from spermatozoa rather than necrotic epithelial cells or leucocytes.

With the initiation of implantation the number of free spermatozoa in the uterine lumina dropped markedly. Some of these were taken up by epithelial cells lining the lumen and the luminal portions of the endometrial glands (Fig. 3). Sperm heads were seen in the epithelium in these sites in $3 / 5$ bats carrying unimplanted uterine embryos and in $5 / 13$ bats bearing implanting or recently implanted embryos. Furthermore, far more spermatozoa were present in the uterine epithelium in some of these animals (Fig. 4) than were ever observed in the oviducal epithelium. Fragments of pycnotic chromatin which may have been derived from spermatozoa were also commonly seen in the uterine epithelium in all of the bats carrying implanting or recently implanted embryos. Since no large scale movement of phagocytic cells into the uterine lumen was noted during this period, one must suspect that many other spermatozoa had been expelled into the cervix. Observations on the zonae pellucidae shed by the uterine blastocysts, when the zonae could be found, provided evidence that there is movement of fluid in the appropriate direction. In 5 bats the discarded zonae were trapped on the cranial side of the expanding blastocysts; however, the zonae were found at the caudal end of the uterine horn in 4 bats (Figs $5 \& 6$ ) and in the cranial end of the cervix in another. The transport of more of these zonae into the cervix appears to have been prevented by closure of the lumen of the right uterine horn which occurred during the early stages of implantation. Some spermatozoa trapped in the uterus by luminal closure also appeared to undergo necrosis while still in the lumen.

Relatively few leucocytes were seen in the cervical lumen of preovulatory females and those carrying tubal ova. Polymorphonuclear leucocytes and sometimes macrophages were observed in the lumen of the cranial end of the cervix in 10/18 females carrying free to recently implanted uterine embryos. The number of cervical leucocytes varied considerably between animals, but in some of these bats large numbers were seen both in the lumen and migrating through the cervical epithelium. Furthermore, in some animals these luminal polymorphonuclear leucocytes and macrophages contained an abundance of phagocytized sperm heads.

\section{Discussion}

A striking feature of reproduction in black mastiff bats is that spermatozoa are so commonly found in the vaginal smears for prolonged periods after the start of breeding activity. Since sperm storage is known to occur in females belonging to two other bat families (the Vespertilionidae and Rhinolophidae; Racey, 1979) consideration must be given to the possibility that spermatozoa released from reservoirs in more proximal regions of the female tract may be partly responsible for these observations in the black mastiff bat. Many of the preovulatory and recently post-ovulatory bats were found to have intact spermatozoa in the uterine horns and the intramural segments of the oviducts, but the question of how long spermatozoa remain viable in those sites could not be addressed. On the other hand, sperm-positive vaginal smears were obtained from bats during periods (e.g. the late luteal phase of the cycle and pregnancy after the start of implantation) when reservoirs of intact spermatozoa were not present in those regions.

Fig. 6. Higher power view of the zona pellucida $(Z)$ shown in Fig. 5. The zona appears to have been trapped here by closure of the lumen. Abundant polymorphonuclear leucocytes, macrophages, and probably the remnants of some granulosa cells, are evident in the cervical lumen to the right. Masson's trichrome, $\times 562$. 
The results of the histological studies indicate that insemination in the black mastiff bat is vaginal. When seminal plugs were found, they were limited to the vagina. Furthermore, in 2 animals with such plugs no spermatozoa were present in the cervices.

Although spermatozoa were frequently observed at the cranial end of the cervix, they were only rarely seen in the remainder of the cervical canal. This suggests that spermatozoa are rapidly transported through the latter after insemination. It also raises a question about the extent to which spermatozoa may subsequently be cleared back into the vagina from more cranial regions of the tract. Some ciliated cells are present in the cervical epithelium, and the caudal two-thirds of the cervix is particularly rich in smooth muscle. The ciliated cells and smooth muscle could play important roles in transporting spermatozoa through the cervix and possibly in preventing their later clearance into the vagina.

Several lines of evidence indicate that female black mastiff bats are receptive to the males at least periodically over extended intervals and at times other than immediately around ovulation. A large proportion of the females mated soon after being housed with the males. This cannot be attributed to the females being induced ovulators or spontaneous ovulators with very short cycles. Many of the females killed soon after both the introduction of males and the onset of breeding activity had CL from one or two previous, non-pregnant cycles. The absence of still older CL in their ovaries and the pronounced cyclic changes that were observed in the endometrium suggest that the cycle length in this species is not very short (J. J. Rasweiler, unpublished observations). The fact that few of these females were in a periovulatory state provides further evidence that they do not exhibit a limited period of receptivity. Finally, some females displayed intense sexual interest in the males, copulated again, or had new vaginal plugs many days after the initiation of breeding activity.

Females of some other bat species are also receptive to the male at times other than immediately around ovulation. A number of vespertilionid and rhinolophid bats are first inseminated many weeks or even months before the occurrence of ovulation (Harrison Matthews, 1937; Wimsatt, 1945, 1969; Pearson et al., 1952; Gopalakrishna \& Madhavan, 1971, 1978; Medway, 1972; Krutzsch, 1975; Racey, 1975, 1979; Myers, 1977; Krishna \& Dominic, 1978; Oxberry, 1979). Nearly all of these bats are known to store spermatozoa in the female tract, but many have been observed to copulate again during the period leading up to ovulation. Vesicular follicles were usually present in their ovaries from the time of the first inseminations, but copulations have been recorded in several vespertilionids even before such follicles were evident (Guthrie, 1933). Spermatozoa have also been observed in the reproductive tracts from other bats (Noctilio albiventris, family Noctilionidae, and Pteropus giganteus, family Pteropodidae) which lacked large preovulatory follicles (Rasweiler, 1978; Towers \& Martin, 1985). When efforts were made to breed captive Phyllostomus discolor (family Phyllostomidae) many of the females were inseminated soon after introduction of the males and continued to exhibit sperm-positive smears, occasionally interrupted by a negative one, for many days in succession (Rasweiler \& Ishiyama, 1973). Another phyllostomid, Carollia, will frequently breed at times other than around ovulation (Bonilla \& Rasweiler, 1974) but does not exhibit extended periods of sperm-positive smears as do females of $M$. ater and $P$. discolor. In Glossophaga soricina (also a phyllostomid bat), however, the onset of receptivity in the female consistently occurred only in close temporal proximity to ovulation (Rasweiler, 1972). Krutzsch \& Crichton (1985) noted the presence of spermatozoa in the reproductive tracts of wildcaught Molossus fortis, non-pregnant and pregnant females, for an extended period but could not determine whether the spermatozoa had been stored or multiple inseminations had taken place.

The uptake of sperm components by the oviducal and uterine epithelial cells of the black mastiff bat, presumably by means of phagocytosis, is unusual but not unique to this species. The same phenomenon has been reported to occur in the oviducts and/or uteri of a variety of other mammals including the rat, mouse, guinea-pig, rabbit, hedgehog, mole, stoat (Kohlbrugge, 1913; Austin, 1959, 1960; Austin \& Bishop, 1959; Chakraborty \& Nelson, 1975) and the bats Rousettus (Kohlbrugge, 1910, 1913), Rhinolophus (Austin \& Bishop, 1959; Austin, 1960; Austin \& Walton, 
1960; Mōri et al., 1982; Uchida et al., 1984), Pipistrellus (Austin \& Bishop, 1959; Austin \& Walton, 1960; Mōri \& Uchida, 1974; Racey, 1975; Krishna, 1984, 1985), and Myotis (Wimsatt et al., 1966; Racey, 1975; Krutzsch et al., 1982). Only in some mice and bats has this been found to involve substantial numbers of spermatozoa. The significance of such uptake by epithelial cells in the female tract, as opposed to other means of sperm disposal, remains to be elucidated. In the case of the black mastiff bat it becomes apparent in the uterus immediately before implantation. This raises the possibility that it may be related to increased endocytotic activity which occurs primarily for other reasons. Endocytosis has been observed in the epithelia of progestational rat and mouse uteri (Enders \& Nelson, 1973; Enders, 1976; Leroy et al., 1976; Parr, 1980), and it has been suggested that this may play a variety of important functions during early pregnancy (see Enders \& Nelson, 1973; Parr \& Parr, 1977). One of these may be to effect closure of the uterus on the blastocysts by removing luminal fluid. Closure of the uterine lumen has been noted during implantation in the black mastiff bat.

I thank members, particularly Mr Param Deoraj and Professor J. S. Kenny, of the Department of Zoology at the University of the West Indies in St Augustine, Trinidad, for generous assistance and the use of departmental facilities during the course of the field work required for this study; and Ms Mary Ann Costa for secretarial assistance. This work was supported by Grants HD-17739 and RR-05396 from the National Institutes of Health.

\section{References}

Austin, C.R. (1959) Entry of spermatozoa into the fallopian-tube mucosa. Nature, Lond. 183, 908-909.

Austin, C.R. (1960) Fate of spermatozoa in the female genital tract. J. Reprod. Fert. 1, 151-156.

Austin, C.R. \& Bishop, M.W.H. (1959) Presence of spermatozoa in the uterine-tube mucosa of bats. $J$. Endocr. 18, viii-ix, Abstr.

Austin, C.R. \& Walton, A.W. (1960) Fertilisation. In Marshall's Physiology of Reproduction, 3rd edn, vol. 1, part 2, pp. 310-416. Ed A. S. Parkes. Longmans, Green \& Co. Ltd, London.

Bonilla, H. de \& Rasweiler, J.J., IV (1974) Breeding activity, preimplantation development, and oviduct histology of the short-tailed fruit bat, Carollia, in captivity. Anat. Rec. 179, 385-404.

Cabrera, A. (1958) Catalogo de los mamiferos de America del Sur. Rev. Mus. Argentino Cienc. Nat. “Bernardino Rivadavia" 4, 1-307.

Chakraborty, J. \& Nelson, L. (1975) Fate of surplus sperm in the fallopian tube of the white mouse. Biol. Reprod. 12, 455-463.

Dolan, P.G. (1982) Systematics of Middle American Mastiff Bats (Molossus). Ph.D. Thesis, Texas Tech University, Lubbock.

Enders, A.C. (1976) Anatomical aspects of implantation. J. Reprod. Fert., Suppl. 25, 1-15.

Enders, A.C. \& Nelson, D.M. (1973) Pinocytotic activity of the uterus of the rat. Am. J. Anat. 138, 277-300.

Gopalakrishna, A. \& Madhavan, A. (1971) Survival of spermatozoa in the female genital tract of the Indian vespertilionid bat, Pipistrellus ceylonicus chrysothrix (Wroughton). Proc. Indian Acad. Sci., Sect. B 73, 43-49.

Gopalakrishna, A. \& Madhavan, A. (1978) Viability of inseminated spermatozoa in the Indian vespertilionid bat Scotophilus healthi (Horsefield). Indian J. exp. Biol. 16, 852-854.
Guthrie, M.J. (1933) The reproductive cycles of some cave bats. J. Mammal. 14, 199-216.

Hall, E.R. \& Kelson, K.R. (1959) The Mammals of North America. Volume 1. Ronald Press, New York.

Harrison Matthews, L. (1937) The female sexual cycle in the British bats Rhinolophus ferrumequinum insulanus Barrett-Hamilton and $R$. hipposideros minutus Montagu. Trans. zool. Soc. Lond. B 23, 224-255.

Horst, R. (1966) Observations on the gular gland of Molossus rufus nigricans. Anat. Rec. 154, 465.

Kohlbrugge, J.H.F. (1910) Der Einfluss der Spermatozoiden auf den Uterus. Ein Beitrag zur Telegonie. Z. Morphol. Anthropol. 12, 359-369.

Kohlbrugge, J.H.F. (1913) Die Verbreitung der Spermatozoiden im weiblichen Körper und im befruchteten Ei. Arch. Entwicklungsmech. Org. 35, 165-188.

Koopman, K.F. (1978) Zoogeography of Peruvian bats with special emphasis on the role of the Andes. Am. Mus. Novitates 265, 1-33.

Krishna, A. (1984) Storage of spermatozoa in the female genital tract of the Indian pigmy pipistrelle bat, Pipistrellus mimus Wroughton. Archs. Biol., Bruxelles 95, 223-229.

Krishna, A. (1985) Reproduction in the Indian pigmy pipistrelle bat, Pipistrellus minimus. J. Zool., Lond. 206, 4l-51.

Krishna, A. \& Dominic, C.J. (1978) Storage of spermatozoa in the female genital tract of the vespertilionid bat, Scotophilus heathi. J. Reprod. Fert. 54, 319-321.

Krutzsch, P.H. (1975) Reproduction of the canyon bat, Pipistrellus hesperus in southwestern United States. Am. J. Anat. 143, 163-200.

Krutzsch, P.H. \& Crichton, E.G. (1985) Observations on the reproductive cycle of female Molossus fortis (Chiroptera: Molossidae) in Puerto Rico. J. Zool., Lond. 207, 137-150. 
Krutzsch, P.H., Crichton, E.G. \& Nagle, R.B. (1982) Studies on prolonged spermatozoa survival in Chiroptera: a morphological examination of storage and clearance of intrauterine and cauda epididymal spermatozoa in the bats Myotis lucifugus and $M$. velifer. Am. J. Anat. 165, 421-434.

Leroy, F., Van Hoeck, J. \& Bogaert, C. (1976) Hormonal control of pinocytosis in the uterine epithelium of the rat. J. Reprod. Fert. 47, 59-62.

Medway, Lord (1972) Reproductive cycles of the flatheaded bats Tylonycteris pachypus and $T$. robustula (Chiroptera: Vespertilionidae) in a humid equatorial environment. Zool. J. Linn, Soc. 51, 33-61.

Mōri, T. \& Uchida, T.A. (1974) Electron microscopic analysis of the mechanism of fertilization in Chiroptera. II. Engulfment of spermatozoa by epithelial cells of the fallopian tube in the Japanese house bat, Pipistrellus abramus. Zool. Mag., Tokyo 83, 163-170.

Mōri, T. \& Uchida, T.A. (1980) Sperm storage in the reproductive tract of the female Japanese longfingered bat, Miniopterus schreibersii fuliginosus. $J$. Reprod. Fert. 58, 429-433.

Mōri, T., Oh, Y.K. \& Uchida, T.A. (1982) Sperm storage in the oviduct of the Japanese greater horseshoe bat, Rhinolophus ferrumequinum nippon. J. Fac. Agr., Kyushu Univ. 27, 47-53.

Myers, P. (1977) Patterns of reproduction in four species of vespertilionid bats in Paraguay. Univ. Calif. Publs Zool. 107, 1-41.

Myers, P. \& Wetzel, R.M. (1983) Systematics and zoogeography of the bats of Chaco Boreal. Misc. Publs Mus. Zool., Univ. Michigan 165, 1-59.

Oxberry, B.A. (1979) Female reproductive patterns in hibernating bats. J. Reprod. Fert. 56, 359-367.

Parr, M.B. (1980) Endocytosis in the uterine epithelium during early pregnancy. Prog. Reprod. Biol. 7, 81-91.

Parr, M.B. \& Parr, E.L. (1977) Endocytosis in the uterine epithelium of the mouse. J. Reprod. Fert. 50, 151-153.

Pearson, O.P., Koford, M.R. \& Pearson, A.K. (1952) Reproduction of the lump-nosed bat (Corynorhinus rafinesquei) in California. J. Mammal. 33, 273-320.

Racey, P.A. (1975) The prolonged survival of spermatozoa in bats. In The Biology of the Male Gamete, pp. 385-416. Eds J. G. Duckett \& P. A. Racey. Academic Press, London.

Racey, P.A. (1979) The prolonged storage and survival of spermatozoa in Chiroptera. J. Reprod. Fert. 56, 391-402.

Racey, P.A., Suzuki, F. \& Medway, Lord (1975) The reiationship between stored spermatozoa and the oviducal epithelium in bats of the genus Tylonycteris. In The Biology of Spermatozoa: Transport, Survival and Fertilising Capacity, pp. 123-133. Eds E. S. E. Hafez \& C. G. Thibault. Karger, Basel.
Rasweiler, J.J., IV (1972) Reproduction in the longtongued bat, Glossophaga soricina. I. Preimplantation development and histology of the oviduct. $J$. Reprod. Fert. 31, 249-262.

Rasweiler, J.J., IV (1978) Unilateral oviductal and uterine reactions in the little bulldog bat, Noctilio albiventris. Biol. Reprod. 19, 467-492.

Rasweiler, J.J., IV \& Ishiyama, V. (1973) Maintaining frugivorous phyllostomatid bats in the laboratory: Phyllostomus, Artibeus and Sturnira. Lab. Anim. Sci. 23, 5661 .

Sansom, G.S. (1932) Notes on some early blastocysts of the South American bat Molossus. Proc. zool. Soc. Lond. 113-118.

Towers, P.A. \& Martin, L. (1985) Some aspects of female reproduction in the grey-headed flying-fox, Pteropus poliocephalus (Megachiroptera: Pteropodidae). Aust. Mammal. 8, 257-263.

Uchida, T.A., Mōri, T. \& Oh, Y.K. (1984) Sperm invasion of the oviducal mucosa, fibroblastic phagocytosis and endometrial sloughing in the Japanese greater horseshoe bat, Rhinolophus ferrumequinum. Cell Tiss. Res. 236, 327-331.

van der Merwe, M., Rautenbach, I.L. \& van der Colf, W.J. (1986) Reproduction in females of the little free-tailed bat, Tadarida [Chaerephon] pumila, in the eastern Transvaal, South Africa. J. Reprod. Fert. 77, 355-364.

Villa-R., B. (1966) Los Murcielagos de Mexico. Instituto de Biologia, Universidad Nacional Autonoma de Mexico, Mexico, D.F.

Wimsatt, W.A. (1945) Notes on breeding behavior, pregnancy and parturition in some vespertilionid bats of the Eastern United States. J. Mammal. 26, 23-33.

Wimsatt, W.A. (1969) Some interrelations of reproduction and hibernation in mammals. Symp. Soc. exp. Biol. 23, 511-549.

Wimsatt, W.A. (1975) Some comparative aspects of implantation. Biol. Reprod. 12, 1-40.

Wimsatt, W.A. (1979) Reproductive asymmetry and unilateral pregnancy in Chiroptera. J. Reprod. Fert. 56, 345-357.

Wimsatt, W.A., Krutzsch, P.H. \& Napolitano, L. (1966) Studies on sperm survival mechanisms in the female reproductive tract of hibernating bats. I. Cytology and ultra-structure of intra-uterine spermatozoa in Myotis lucifugus. Am. J. Anat. 119, 2560.

Received 19 August 1986 